\title{
A AVALIACCÃO DA GERAÇÃO DE SEDIMENTOS AO LONGO DA BACIA HIDROGRẢFICA DO RIBEIRÃO DO CARMO. POTENCIAL NATURAL DE EROSÃO, FEIÇÕES MORFOLÓGICAS E CICATRIZES DE MOVIMENTOS DE MASSA.
}

\author{
THE SEDIMENT GENERATION OVER THE WATERSHED OF RIBEIRÃO DO CARMO. \\ NATURAL POTENTIAL OF EROSION, MORPHOLOGICAL FEATURES AND SCARS OF \\ MASS MOVEMENT.
}

\section{Leonardo Andrade de SOUZA ${ }^{1}$, Frederico Garcia SOBREIRA ${ }^{2}$}

(1) Programa de Pós-graduação em Geotecnia - Universidade Federal de Ouro Preto. Rua Oito de Março, 117, Bairro

Maquiné, 35420-000 - Mariana (MG). Endereço eletrônico: leonardo@zemlya.com.br

(2) Universidade Federal de Ouro Preto, Escola de Minas, Departamento de Engenharia Ambiental. Escola de Minas Campus Universitário do Morro do Cruzeiro, Bauxita, 35400-000 - Ouro Preto (MG). Endereço eletrônico:

sobreira@degeo.ufop.br

\author{
Introdução \\ A Bacia do Ribeirão do Carmo (BRHC) \\ Erosão laminar e perda de solo na BHRC \\ Materiais e Métodos \\ Obtenção dos Fatores E, K, L, S \\ Potencial natural de erosão (PNE) da BHRC \\ Cálculo da perda de solo na BHRC \\ Inventário de feições morfológicas e cicatrizes de movimentos de massa \\ Conclusão \\ Referências
}

\begin{abstract}
RESUMO - A dinâmica da geração e transporte de sedimentos superficiais em uma área urbanizada difere significativamente da mesma dinâmica para áreas rurais, o que torna a sua análise uma tarefa complexa por envolver necessariamente inúmeros fatores de ordem física, meteorológica e antrópica. A Bacia Hidrográfica do Ribeirão do Carmo (BHRC) está localizada nos municípios de Ouro Preto e Mariana, tendo uma área é de $351,60 \mathrm{~km}^{2}$ e um perímetro de 139,22 km. A abordagem realizada teve como pressuposto a elaboração da carta de suscetibilidade a erosão natural, a partir da aplicação da Equação Universal de Perda do Solo (EUPS), para a predição da média anual de perda de solo causada pela erosão laminar, somado à identificação do maior número possível de fontes geradoras de sedimentos (feições morfológicas e cicatrizes de movimentos de massa) ao longo de toda a bacia. Os estudos relacionados ao entendimento da transformação do meio físico ganham importância à medida que podem auxiliar em uma gestão ambiental sustentável, sendo para tal necessário correlacionar o diagnóstico do meio físico, com o modelo de desenvolvimento vigente, apontando tanto os aspectos falhos no planejamento e gestão dos recursos, quanto diretrizes para uma adequada ocupação do solo urbano e rural.
\end{abstract}

Palavras-chave: Suscetibilidade, Erosão, Ordenamento Territorial.

\begin{abstract}
The dynamic of the generation and transport of superficial sediments in an urban area differs significantly from the same dynamics for rural areas, what turns their analysis a complex task because it involves numerous factors of physical, meteorological and anthropogenic order. The watershed of Ribeirão do Carmo (BHRC) is located in the towns of Ouro Preto and Mariana, having an area of $351,60 \mathrm{~km}^{2}$ and is has a perimeter of 139,22 kilometers. The accomplished approach had presupposed the elaboration of the letter of susceptibility to natural erosion, from the application of Universal Soil Loss Equation (USLE), for predicting of the soil loss annual average caused by sheet erosion, coupled with the identification of greater number of possible sources of sediment (features morphological and scars of mass movement) along the entire basin. The studies related to understanding of the physical environment become important as they can help in sustainable environmental management, being to such necessary to correlate the diagnosis of the physical environment, with the current development model, pointing both flawed aspects of the planning and management of the resources, about guidelines for an adequate occupation of the urban and rural soil.
\end{abstract}

Keywords: Susceptibility, Erosion, Spatial Planning.

\section{INTRODUÇÃO}

Compreender a dinâmica dos processos erosivos e sedimentológicos é uma tarefa complexa por envolver necessariamente inúmeros fatores de ordem física, metereológica e antrópica. Tognon (1984) define os processos erosivos como um conjunto de fatores físicos, químicos e/ou biológicos, naturais, responsáveis pelo modelado do relevo terrestre, na maioria, diretamente ligados ao clima (chuvas, rios, água subterrânea, correntes marinhas, ondas, geleiras, ventos), sendo que estes podem ser acelerados artificialmente pelo homem, por desmatamentos, retaludamentos em obras lineares, construção de edificações, ou outras modificações no manto de intemperismo em geral.

Além dos fatores naturais, o uso do solo e a ação antrópica com o propósito de promover 
desenvolvimento para uma área que se pretenda ocupar, seja ela rural ou urbana, inevitavelmente causam impactos aos ambientes bióticos e abióticos.

Silva et al. (2004) ressaltam que as taxas de erosão nos diferentes tipos de material são muito variáveis, dependendo entre outros fatores da composição química, da consistência dos materiais, do comportamento na infiltração e no escoamento das águas superficiais e subsuperficiais, da espessura da camada de rocha e solo, da declividade, das famílias de descontinuidades e do clima local.

Em geral, distinguem-se duas formas de abordagem para os processos erosivos: erosão natural ou geológica, que é a erosão que se desenvolve em condições de equilíbrio com a formação do solo (também conhecida como erosão laminar), e erosão acelerada, cuja intensidade é superior à da formação do solo, não permitindo a sua recuperação natural (também conhecida como erosão linear). Neste caso pode haver, além da evolução natural do terreno, grande influência humana (antrópica).

No âmbito urbano, a remoção da cobertura vegetal e a consequente exposição do solo ocasionam alterações no ciclo hidrológico, em decorrência da diminuição da porcentagem de água infiltrada e o aumento do escoamento superficial, aumentando-se a produção de sedimentos com consequente empobrecimento dos solos lixiviados, assoreamentos e/ou contaminações dos cursos de água. A dinâmica do transporte de sedimentos superficiais em uma área urbanizada difere significativamente da dinâmica da erosão para áreas rurais. Para as áreas urbanas pode-se apontar como fatores preponderantes:

- Concentração do fluxo superficial, associado ou não a deficiência do sistema de micro e macrodrenagem;

- Movimentação de terras nas áreas ocupadas, desde ocupações pontuais com a construção de domicílios, até grandes obras de engenharia.

Já para as áreas rurais os processos erosivos estão relacionados ao uso do meio físico e, embora o regime hidrológico seja alterado em menor intensidade, o tipo de cultura instalada e o manejo do solo podem acarretar na exposição inadequada do solo, tendo como consequência o carreamento de volumes significativos de sedimentos para os cursos de água.

Neste estudo, a abordagem dos processos erosivos como elemento do diagnóstico ambiental da Bacia Hidrográfica do Ribeirão do Carmo (BHRC) teve como pressuposto, especificamente, a elaboração da carta de suscetibilidade a erosão natural associada ao uso e ocupação atual do solo somando-se a esta à identificação das feições morfológicas e cicatrizes de movimentos de massa indicativas de fontes de geração de sedimentos pretéritas e atuais, ao longo da BHRC. Os produtos finais compreenderam as cartas derivadas da integração dos produtos intermediários gerados, e foram confrontados com os sérios problemas de assoreamento identificado no exutório da BHRC, após a instalação da Pequena Central Hidrelétrica $(\mathrm{PCH})$ Furquim.

\section{A BACIA DO RIBEIRÃO DO CARMO (BRHC)}

A Bacia Hidrográfica do Ribeirão do Carmo (BHRC) localiza-se nos municípios de Ouro Preto e Mariana e pertence à bacia regional do rio Piranga, que por sua vez é uma das cabeceiras da bacia do rio Doce, tendo uma área é de 351,60 $\mathrm{km} 2$ e um perímetro de 139,22 km (Figura 1).

Fisiograficamente, a BHRC corresponde a um segmento pertencente ao Cráton São Francisco Meridional, situada no extremo leste do Quadrilátero Ferrífero e posicionado, segundo CPRM (1993), na Zona limítrofe entre duas importantes Províncias geológicas do escudo brasileiro, a Província Geotectônica São Francisco, a oeste, e a Província Geotectônica Mantiqueira, a leste. A Província Geotectônica São Francisco, que abrange a maior parte da área, reúne agrupamentos de idades e ambiências diversas, sendo que na área de Mariana ocorrem terrenos "granito-greenstone", representados por uma sequência vulcano-sedimentar do Supergrupo Rio das Velhas (Arqueano), rochas granitóides do Complexo Santa Bárbara (Arqueano), a sequência clasto-química do Supergrupo Minas (Proterozoico), a sequência dominantemente clástica do Grupo Itacolomi e as coberturas fanerozóicas terciárias e detríticas recentes, estas representadas por depósitos detríticos-lateríticos e aluviais. Já a Província Geotectônica Mantiqueira, ocorre em uma pequena faixa a leste da Bacia, reunindo gnaisses bandados do Complexo Mantiqueira e granulitos do Complexo Acaiaca. 


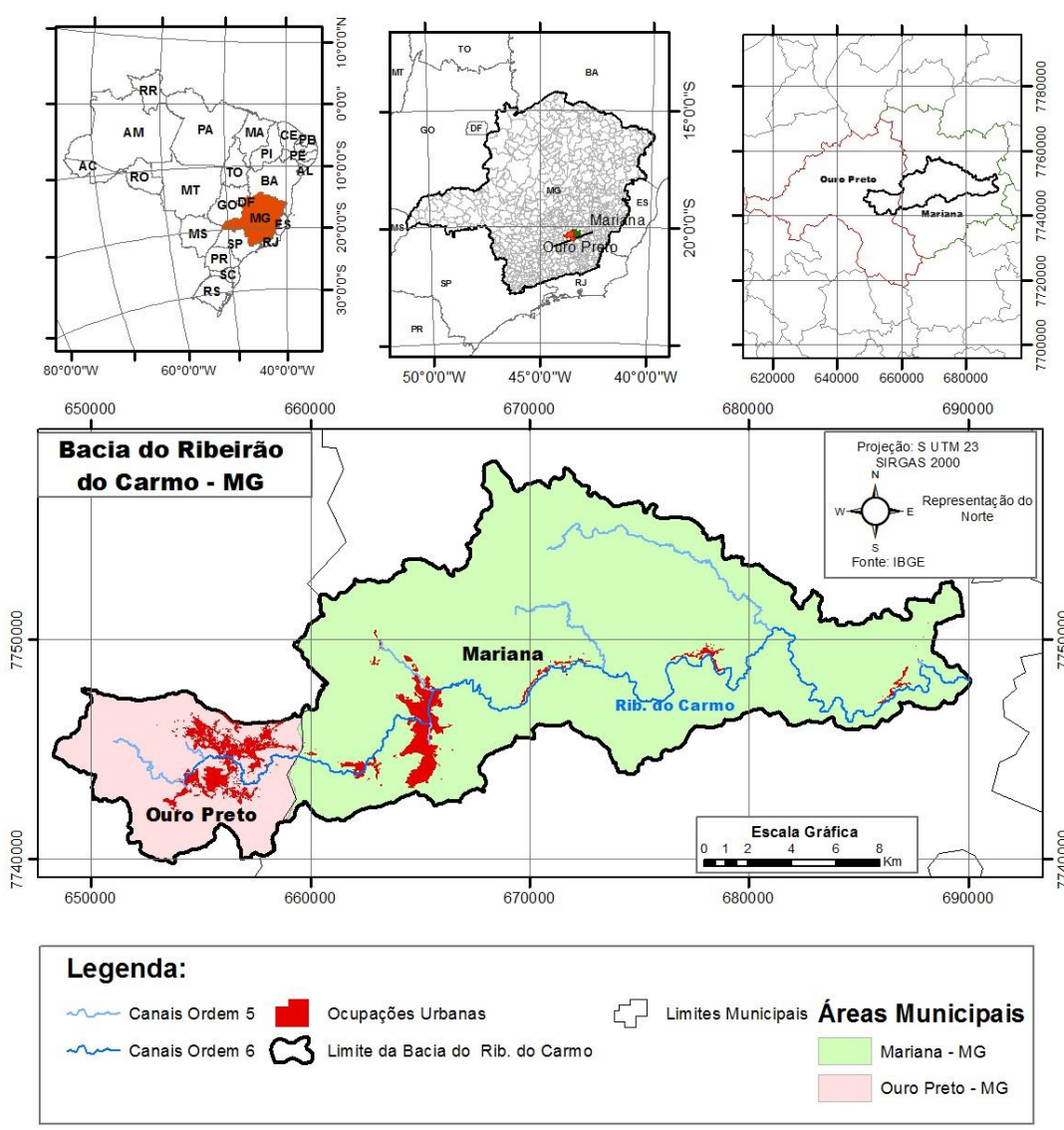

Figura 1 - Bacia Hidrográfica do Ribeirão do Carmo no contexto de Minas Gerais, com os limites municipais e a ocupação urbana (sedes municipais e distritos).

clástica do Grupo Itacolomi e as coberturas fanerozóicas terciárias e detríticas recentes, estas representadas por depósitos detríticos-lateríticos e aluviais. Já a Província Geotectônica Mantiqueira, ocorre em uma pequena faixa a leste da Bacia, reunindo gnaisses bandados do Complexo Mantiqueira e granulitos do Complexo Acaiaca.

Os principais elementos da paisagem são a Serra do Itacolomi e a Serra de Ouro Preto, divisor de duas grandes bacias de drenagem regionais (rios das Velhas e Doce). Duas unidades geomorfológicas podem ser diferenciadas: O Quadrilátero Ferrífero e os Planaltos Dissecados. A primeira unidade é evidenciada nas cabeceiras, a oeste, onde relevo é mais dissecado e condicionado estruturalmente, com substrato rochoso composto por formações metassedimentares neoproterozoicas características do Quadrilátero Ferrífero (filitos, quartzitos, xistos, formação ferrífera bandada e dolomitos) e solos pouco espessos, predominando neossolos litólicos, cambissolos e afloramentos rochosos. Neste setor o ribeirão é bem encaixado e com o leito mais declivoso. As altitudes médias giram em torno de 1.400-1.600 m (CPRM, 1993), e ponto culminante no Pico do Itacolomi $(1.772 \mathrm{~m})$. O controle estrutural na morfologia é marcante, e são descritos relevos tipo sinclinais suspensos e anticlinais esvaziados além de cristas estruturais do tipo hogback.

A Segunda unidade ocupa espacialmente a porção centro-leste, o relevo é ondulado a suave ondulado, com predomínio de solos mais espessos (argissolos e latossolos) podendo-se inserir a região a um domínio morfoestrutural com exposição de rochas cristalinas, deformadas e deslocadas do embasamento, atingidas por sucessivos estágios de erosão e submetidos a processos intempéricos que produziram pacotes de alteração evoluídos (RADAMBRASIL, 1983). O intenso processo de dissecação fluvial foi responsável pela origem das formas de colinas e cristas com vales encaixados e/ou de fundo chato (CPRM, 1993). São mais frequentes pequenas planícies de inundação e quase não há saltos consideráveis ao longo do leito do ribeirão. Neste setor a drenagem ganha um padrão dendrítico e o curso principal recebe vários afluentes. Nessa unidade as altitudes são muito variáveis, oscilando entre 1.000 e 1.200 $\mathrm{m}$ nas cristas e 500-800 m nos vales. 


\section{EROSÃO LAMINAR E PERDA DE SOLO NA BHRC}

Processos erosivos laminares, ou em lençol, são causados pelo escoamento difuso das águas das chuvas, resultando na remoção progressiva e uniforme dos horizontes superficiais do solo, principalmente, em áreas com declividades medianas e acentuadas, onde ocorreu a remoção da cobertura vegetal original, cujo reflexo direto remete ao transporte de sedimentos ao longo das encostas, até as porções mais baixas dos canais, provocando seu assoreamento.

\section{MATERIAIS E MÉTODOS}

Atualmente tem-se uma gama de técnicas e procedimentos metodológicos para $\mathrm{o}$ reconhecimento, modelagem e quantificação da dinâmica dos processos erosivos. São diversos os modelos matemáticos utilizados no estudo da erosão laminar. Os mais utilizados são os modelos empíricos, cuja metodologia estabelece correlações entre o volume de sedimentos realmente liberados pela erosão hídrica, e o volume calculado por equações matemáticas que englobam os vários fatores do processo erosivo.

Neste estudo optou-se por obter a susceptibilidade à erosão da Bacia do Ribeirão do Carmo a partir da aplicação da Equação Universal de Perda do Solo (EUPS), desenvolvida por pesquisadores do Serviço de Pesquisa Agrícola (ARS) do Departamento de Agricultura dos Estados Unidos (USDA) (Wischmeier \& Smith, 1978). Este procedimento é um dos mais aceitos e utilizados para o cálculo de perdas de solo, sendo um método para a predição da média anual de perda de solo causada por erosão laminar.

A EUPS baseia-se em inúmeros procedimentos de campo e aborda os quatro maiores fatores responsáveis pelos processos erosivos lineares e superficiais (clima, solo, topografia, uso e manejo do solo). Foram consideradas na análise, as seguintes informações: Fator R - Erosividade da Chuva, Fator K - Erodibilidade do Solo, Fator LS, Fator C - Uso e Manejo, Fator P - Prática Conservação. Cada uma destas informações foi estruturada na forma de uma grade.

A EUPS é definida pela equação:

$$
A=\text { R.K.L.S.C.P }
$$

Onde:

$\mathrm{A}=$ perda de solo, em $\mathrm{t} /$ (ha.ano);

$\mathrm{R}=$ fator erosividade da chuva, em MJ.mm/(ha.h.ano);

$\mathrm{K}=$ fator erodibilidade do solo, em
t.h/(MJ.mm);

$\mathrm{L}=$ fator comprimento de rampa, baseado nos valores, em metros, do comprimento de rampa (adimensional);

$\mathrm{S}=$ fator declividade, baseado nos valores, em porcentagem, da declividade (adimensional);

$\mathrm{C}=$ fator uso e manejo (adimensional); e,

$\mathrm{P}=$ fator práticas conservacionistas (adimensional).

Para a determinação dos vários fatores envolvidos na EUPS foram utilizadas as seguintes fontes e bases cartográficas compiladas ou geradas:

- Séries históricas de pluviosidade $(25$ anos) com médias anuais e mensais da região, obtidas no site Hidroweb (hidroweb.ana.gov.br),

- Cartas geológicas do Quadrilátero Ferrífero (CODEMIG, 2005 Mapas Geológicos de Ouro Preto e Mariana), na escala 1:50.000) e CPRM (1993), na escala 1: 100.000 ,

- Carta pedológica em escala 1:50.000. Buscou-se a caracterização pedológica da BHRC a partir de informações morfométricas determinadas com o uso de Sistemas de Informações Geográficas. Foram utilizados quatro parâmetros morfométricos principais, a altimetria (MDE), a declividade, a área de contribuição e a orientação de vertentes, realçados por meio de composição colorida. Posteriormente os resultados foram validados com trabalhos de campo para simples reconhecimento dos terrenos.

- Cartas topográficas do IBGE em escala 1:50.000,

- Modelo digital de elevação, obtido pelo processamento da base topográfica,

- Carta de uso do solo, obtido pela interpretação e processamento de imagens ASTER (2005) através do Índice de Vegetação da Diferença Normalizada (NVDI) e trabalhos de campo, 
- Informações obtidas em outros trabalhos da literatura especializada.

- A rede hidrográfica da Bacia do Ribeirão do Carmo foi inicialmente obtida a partir do mapa topográfico 1:50.000 do IBGE (Folhas Ouro Preto, Mariana, 1986). Entretanto, optou-se pela interpretação das fotos aéreas na escala 1:25.000 (Esteio, 1986) de toda a área, que posteriormente foi vetorizada e corrigida através da correlação e sobreposição ao mosaico de 25 ortofotos na escala 1:10.000 (CEMIG, 1987). Posterior- mente a vetorização, procedeu-se hierarquização dos canais por ordem. As bacias interiores que compõem a BHRC foram delimitadas considerando a metodologia para o ordenamento de cursos d'água proposto por Strahler (1957). A partir da classificação o Ribeirão do Carmo foi definido como um afluente de ordem 6 e a BHRC foi reclassificada em bacias interiores com cursos d'água de ordem 3 e superior a esta para delimitação das bacias de interesse do estudo.

\section{OBTENÇÃO DOS FATORES H, K, L, S}

Para obtenção do Fator R - Erosividade da Chuva foram utilizadas grades pluviométricas com as médias anuais e mensais em um período de 25 anos. Foram identificadas 49 estações pluviométricas com séries históricas (site hidroweb) disponíveis em uma distância de até $40 \mathrm{~km}$ em relação aos limites da Bacia do Ribeirão do Carmo.

Os dados de chuva de cada estação foram analisados de modo a selecionar períodos comuns de registro ao longo dos anos. No caso deste trabalho foram selecionadas 15 estações pluviométricas com registros de chuvas completos ente os anos de 1984 e 2009.

Para a determinação do valor médio do índice de erosividade foram utilizadas grades pluviométricas com as médias anuais e mensais do mesmo período de 25 anos, por meio da relação entre a média mensal e a média anual de precipitação. A interpolação dos valores das grades pluviométricas com as médias anuais e mensais das estações pluviométricas possibilitou a geração da carta de pluviosidade anual média da BHRC (Figura 2).

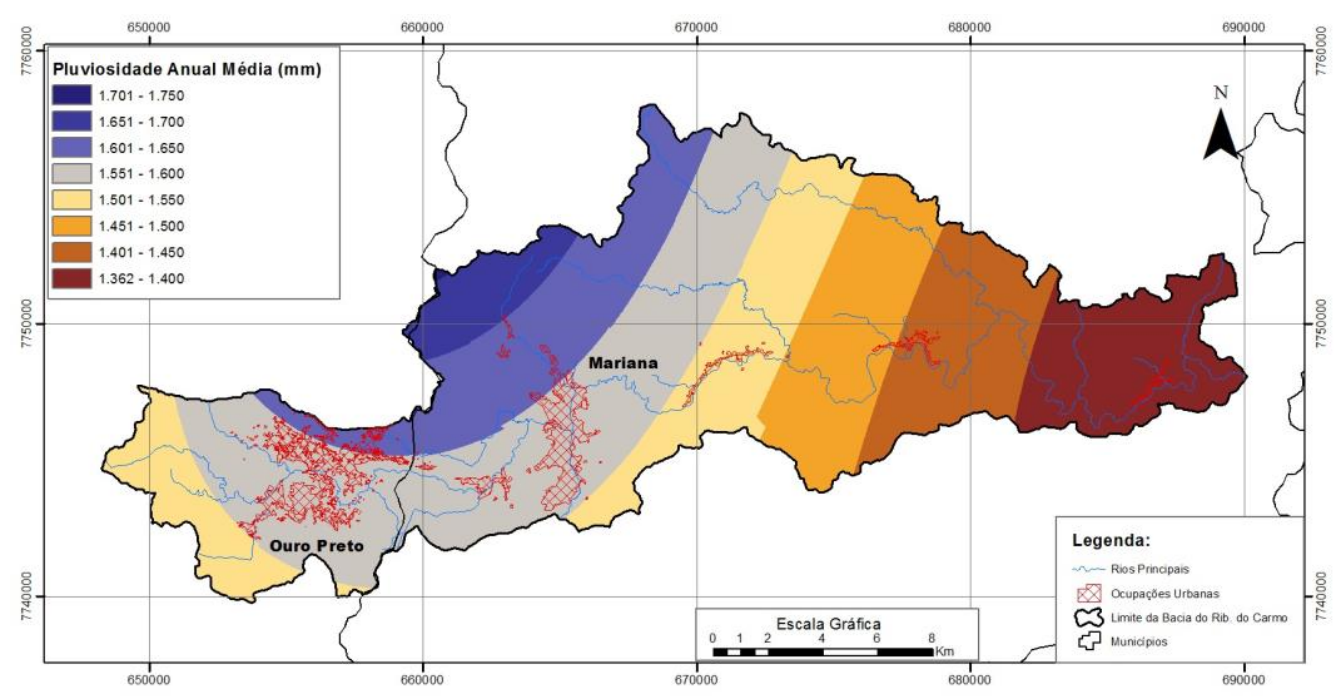

Figura 2 - Carta de pluviosidade anual média da Bacia Hidrográfica do Ribeirão do Carmo gerada através da interpolação das médias anuais de precipitação entre os anos de 1984 e 2009.

Para o cálculo da média mensal do índice de erosividade foi empregada à equação proposta por Lombardi Neto \& Moldenhauer (1992, segundo Bertoni \& Lombardi Neto, 1993). A erodibilidade dos terrenos, solos ou rochas, pode ser avaliada a partir de suas propriedades químicas e físicas, havendo na bibliografia várias sugestões de ponderação e hierar- quização para diferentes tipos de solos e rochas, segundo suas propriedades (MOPT, 1992, Cooke \& Doorkamp, 1990 e Lombardi Neto \& Bertoni, 1975).

$$
E I_{25}=67,355\left(\frac{r^{2}}{P}\right)^{0.85}
$$

Onde: 
- EI25 = média mensal do índice de erosividade, em MJ.mm/(ha.h);

- $\mathrm{r}=$ média do total mensal de precipitação, em $\mathrm{mm}$;

- $\mathrm{P}=$ média do total anual de precipitação, em $\mathrm{mm}$,

Este índice é expresso em toneladas por hectare por unidade de pluviosidade $\mathrm{EI}_{25}$.

Para obtenção do Fator K - Erodibilidade do Solo foi necessário utilizar a carta pedológica da área, sendo que os valores atribuídos a $\mathrm{K}$ foram obtidos e adaptados do mapa pedológico elaborado nesta análise e, principalmente, de estudos já desenvolvidos na região e em outras áreas do país, a partir dos critérios estabelecidos pela EMBRAPA (2006), levandose em consideração o 10 nível categórico (ordens) do Sistema Brasileiro de Classificação de Solos: Argissolos, Cambissolos, Gleissolos, Latossolos e Neossolos, etc.

A seguir tem-se uma descrição mais detalhada de cada uma dessas classes, ressaltando aspectos ligados ao potencial para utilização e suscetibilidade à erosão. O Quadro 1 mostra os índices de erodibilidade adotados para cada tipo de solo e as fontes bibliográficas onde foram obtidos estes valores, resultados de diferentes estudos realizados ao longo do país.

Quadro 1 - Índices de erodibilidade adotados e respectivas fontes bibliográficas utilizadas como referência.

\begin{tabular}{|c|c|c|l|}
\hline Solo Original & Correspondente & $\mathbf{K}(\mathbf{t} / \mathbf{h} / \mathbf{m j} \mathbf{j} \mathbf{m m})$ & \multicolumn{1}{|c|}{ Fonte } \\
\hline MX & CXbe & 0,0441 & Ribeiro \& Alves (2007). \\
\hline CX & CXbd & 0,0115 & Denardin (1990) e Silva et al. (2000). \\
\hline CX & CXbd & 0,0260 & Castro Júnior (2008). \\
\hline GMd & ${ }^{(1)} \mathrm{GM}$ & 0,0044 & Ribeiro \& Alves (2007). \\
\hline LAw & ${ }^{(1)}$ LA & 0,0110 & Medina \& Oliveira Júnior (segundo Silva et al., 2000). \\
\hline $\begin{array}{c}\text { LVdf; LVwf; } \\
\text { LVj }\end{array}$ & LVdf & 0,0120 & Denardin (1990) e Silva et al. (2000). \\
\hline LVef & LVef & 0,0040 & Hernani et al. (1997). \\
\hline LVd & LVd & 0,0090 & Denardin (1990) e Silva et al. (2000). \\
\hline LVAw; LVw & LVAw & 0,0020 & Denardin (1990) e Silva et al. (2000). \\
\hline LVAd & LVAd & 0,0100 & Silva et al. (2000). \\
\hline LVAd & LVAd & 0,016 & Castro Júnior (2008). \\
\hline RUbd & ${ }^{(1)}$ RU & 0,0420 & Ribeiro \& Alves (2007). \\
\hline RLd & ${ }^{(1)}$ RL & 0,0400 & Ribeiro \& Alves (2007). \\
\hline RLd & ${ }^{(1)}$ RL & 0,0450 & Castro Júnior (2008). \\
\hline PVAd & PVAd & 0,0270 & Marques (1996). \\
\hline PVAe & PVAe & 0,0140 & Marques (1996). \\
\hline PVd & PVd & 0,0340 & Marques (1996). \\
\hline
\end{tabular}

A partir da análise destes índices de erodibilidade e da sua correlação com os solos da Bacia do Ribeirão do Carmo, mesmo quando não representáveis cartograficamente em decor- rência da escala adotada (1:50.000) chegou-se a valores de erodibilidade para os solos da Bacia do Ribeirão do Carmo (Quadro 2).

Como tanto o comprimento do declive, como o seu gradiente afetam a intensidade de erosão pela água, estes dois fatores têm sido pesquisados separadamente e são representados na equação de perdas de solo por L e S, respectivamente. No entanto, para aplicação prática, é mais conveniente considerá-los conjuntamente como um fator topográfico: Way (1978, segundo MOPT, 1992) apresenta um ábaco onde pode ser obtido o fator L.S a partir dos valores de comprimento e declive das vertentes. Bertoni (1959) desenvolveu a seguinte expressão:

$$
\mathrm{LS}=0.00984 . \mathrm{L}^{0.63} \cdot \mathrm{S}^{1.18}
$$

Onde:

$\mathrm{L}=$ Comprimento da vertente em metros;

$\mathrm{S}=$ Declividade expressa em porcentagem. 
Quadro 2 - Classes de solo e índices de erodibilidade adotados na BHRC.

\begin{tabular}{|c|c|c|c|}
\hline CLASSES & UNIDADES DE SOLO & DESCRIÇÃO RESUMIDA & $\mathrm{K}(\mathrm{t} / \mathrm{h} / \mathbf{m j} . \mathbf{m m})$ \\
\hline Neossolo Litólico & RLd & Distrófico, relevo forte ondulado e montanhoso. & 0,0400 \\
\hline Cambissolo & CXbd & $\begin{array}{l}\text { CXbd1 a CXbd } 8 \text { - Tb distrófico com Neossolo } \\
\text { Litólico distrófico com Afloramento de Rocha, } \\
\text { relevo forte ondulado e montanhoso. }\end{array}$ & 0,046 \\
\hline $\begin{array}{l}\text { Argissolos- } \\
\text { Latossolos }\end{array}$ & LVAd & $\begin{array}{l}\text { LVAd1 a LVAd8 - Latossolo Vermelho- } \\
\text { Amarelo distrófico, relevo ondulado e suave } \\
\text { ondulado. }\end{array}$ & 0,01 \\
\hline $\begin{array}{c}\text { Neossolos Flúvicos - } \\
\text { Gleissolos }\end{array}$ & GXbd & Gleissolo Háplico Tb distrófico, relevo plano. & 0,0044 \\
\hline $\begin{array}{l}\text { Afloramentos } \\
\text { rochosos }\end{array}$ & AR & $\begin{array}{l}\text { Associação de Afloramento de Rocha com } \\
\text { Cambissolo Háplico Tb distrófico com } \\
\text { Neossolo Litólico distrófico, relevo ondulado, } \\
\text { forte ondulado e montanhoso. }\end{array}$ & -1 \\
\hline
\end{tabular}

Wischimeier \& Smith (1978) apresentaram uma equação única para $\mathrm{L}$ e $\mathrm{S}$ (sistema internacional), calculados conforme a Equação a seguir:

$$
L S=\left(\frac{L^{\frac{1}{2}}}{100}\right) \times\left(1,36+0,97 \cdot S+0,1385 \cdot S^{2}\right)(4)
$$

Onde:

L é o comprimento do declive em metros e;

$\mathrm{S}$ é o grau do declive em porcentagem.

Para a determinação do fator LS da BHRC a equação utilizada foi proposta por Moore \& Burch (1986a; 1986b) onde o fator topográfico LS deriva da relação entre o acúmulo de fluxo (ou área de contribuição) e a declividade da bacia hidrográfica.

$$
L S=\left(\frac{\text { FlowAccumulation } \times \text { CellSize }}{22.13}\right)^{0,4} \times\left(\frac{\operatorname{sen}(\text { Slope })}{0,0896}\right)^{1,3}
$$

Onde:

- FlowAccumulation é o acúmulo de fluxo ou área de contribuição;

- CellSize é o tamanho da célula do modelo digital de elevação usado no presente estudo;

- Slope é a declividade calculada para cada pixel.

Neste trabalho, para obtenção do Fator LS, utilizou-se o modelo digital de elevação, a partir do qual tem-se a grade de área de contribuição e a declividade, que são os planos de informação necessários para obtenção do fator. Assim, a expressão da álgebra de mapas empregada para a obtenção do fator topográfico LS foi:

$$
\mathrm{LS}=\operatorname{Pow}([\text { flowaccgrid }] * 25 / 22.13,0.4) * \operatorname{Pow}(\operatorname{Sin}([\text { slope }] * \pi / 180.0) / 0.0896,1.3)
$$

\section{POTENCIAL NATURAL DE EROSÃO (PNE) DA BRHC}

A partir da determinação dos fatores $\mathrm{R}$ erosividade da chuva, $\mathrm{K}$ - erodibilidade do solo e LS - fator topográfico foi possível o cálculo do Potencial Natural de Erosão (PNE), a partir da equação:

$$
\text { PNE = R.K.L.S }
$$

A Figura 3 reproduz os resultados alcançados a partir do processamento das informações anteriormente calculadas e da equação do potencial natural à erosão, ao longo da Bacia Hidrográfica do Ribeirão do Carmo e suas principais bacias interiores.

Alguns trabalhos propõem a classificação dos solos quanto ao potencial natural de erosão determinando intervalos de perda de solo para o parâmetro de PNE calculado.

A classificação do PNE da bacia do Ribeirão do Carmo levou em consideração a proposição de Valério Filho (1994), que estabelece 4 classes para a interpretação dos resultados alcançados no cálculo do Potencial Natural a Erosão (Quadro 3).

Para uma melhor visualização dos resultados obtidos após o processamento, os dados foram calculados para a área total da BHRC e para as bacias interiores conforme descrição anterior (Quadro 4). 


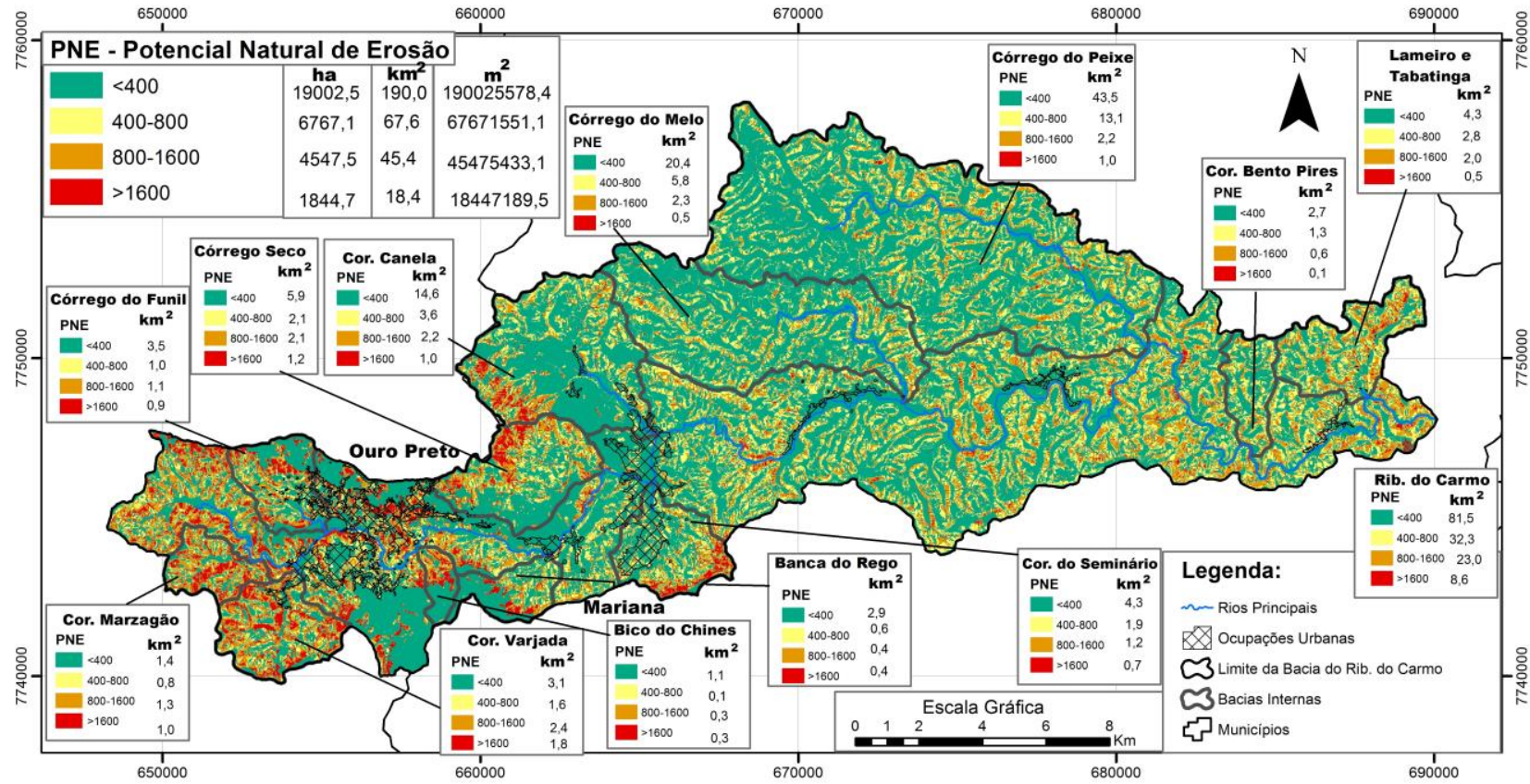

Figura 3 - Carta do Potencial Natural à Erosão da Bacia do Ribeirão do Carmo.

Quadro 3 - Classificação dos solos quanto ao potencial natural de erosão.

\begin{tabular}{|c|c|}
\hline Intervalo de Perda de Solo $\left(\mathbf{t ~ h a}^{-\mathbf{1}} \mathbf{a n o}^{-\mathbf{1}}\right)$ & Classe \\
\hline$<\mathbf{4 0 0}$ & FRACO \\
\hline $\mathbf{4 0 0}-\mathbf{8 0 0}$ & MODERADO \\
\hline $\mathbf{8 0 0}-\mathbf{1 6 0 0}$ & MODERADO A FORTE \\
\hline$>\mathbf{1 6 0 0}$ & FORTE \\
\hline
\end{tabular}

Quadro 4 - Classificação dos solos quanto ao potencial natural de erosão ao longo da Bacia do Ribeirão do Carmo e principais bacias interiores.

\begin{tabular}{|c|c|c|c|c|}
\hline & \multicolumn{4}{|c|}{ ÁREA DAS CLASSES DE PNE $\left(\mathbf{k m}^{\mathbf{2}}\right)$} \\
\hline $\begin{array}{c}\text { BACIA } \\
\text { HIDROGRÁFICA }\end{array}$ & Fraco & Moderado & Moderado a Forte & Forte \\
\hline Ribeirão do Carmo & 190,02 & 67,67 & 45,47 & 18,4 \\
\hline Córrego Marzagão & 1,46 & 0,83 & 1,38 & 1,04 \\
\hline Córrego Varjada & 3,12 & 1,68 & 2,41 & 1,88 \\
\hline Ribeirão do Funil & 3,56 & 1,02 & 1,18 & 0,91 \\
\hline Córrego Bico do Chinês & 1,19 & 0,18 & 0,32 & 0,32 \\
\hline Córrego Banca do Rego & 2,92 & 0,68 & 0,46 & 0,41 \\
\hline Córrego Seco & 5,93 & 2,14 & 2,12 & 1,20 \\
\hline Córrego do Seminário & 4,38 & 1,90 & 1,28 & 0,75 \\
\hline Córrego Canela & 14,64 & 3,62 & 2,28 & 1,04 \\
\hline Córrego do Melo & 20,48 & 5,87 & 2,30 & 0,51 \\
\hline Ribeirão do Peixe & 43,53 & 13,19 & 6,04 & 1,08 \\
\hline Córrego Bento Pires & 2,79 & 1,33 & 0,62 & 2,11 \\
\hline Córregos Lameiro e & 4,30 & 0,51 & 2,81 & 29,65 \\
\hline Tabatinga & 298,32 & 100,62 & 68,67 & \\
\hline Total: & & & & \\
\hline
\end{tabular}




\section{CÁlCULO DA PERDA DE SOLO NA BRHC}

Para a complementação das análises passouse a obtenção do Fator C - Uso e Manejo. Os fatores de uso e manejo e as práticas conservacionistas podem ser analisados também conjuntamente através de cartas de uso e ocupação do solo. O U.S Soil Conservation sugere tabelas para valores do índice $\mathrm{C}$, de acordo com a cobertura arbórea e a porcentagem de área coberta, e do índice $\mathrm{P}$, segundo o tipo de cultivo e os declives envolvidos (MOPT, 1992). Para este trabalho foi utilizada a carta de uso do solo produzida na escala 1:10.000.

Bertoni \& Lombardi Neto (1985) e Righetto (1998) propõem os seguintes índices para os fatores $\mathrm{C}$ e $\mathrm{P}$ no cálculo da perda de solo (Quadro 5).

Quadro 5 - fatores C e P no cálculo da perda de solo.

\begin{tabular}{|l|c|c|}
\hline \multicolumn{1}{|c|}{ USO DO SOLO } & FATOR C & FATOR P \\
\hline Florestas & 0,010 & 0,1 \\
\hline Campos & 0,26 & 0,4 \\
\hline Agricultura & 0,29 & 0,7 \\
\hline Agricultura Irrigada & 0,36 & 1,0 \\
\hline Solos Expostos & 0,404 & 1,0 \\
\hline
\end{tabular}

Outras propostas para o Fator Uso e Manejo foram encontradas na literatura nos trabalhos de Bellinazi Jr et al. (1981), Bertolini \& Lombardi Neto (1993), Pinto (1995), Ribeiro (2000) e
Castro Júnior (2008). O Quadro 6 mostra os índices adotados para o Fator C - Uso e Manejo do Solo na a Bacia do Ribeirão do Carmo.

Quadro 6 - Índices adotados para o fator Uso e Manejo na BHRC.

\begin{tabular}{|c|l|c|}
\hline CLASSE & \multicolumn{1}{|c|}{ USO DO SOLO } & SOLO \\
\hline $\mathbf{1}$ & Mineração & 0,300 \\
\hline $\mathbf{2}$ & Afloramento Rochoso & 0.000001 \\
\hline $\mathbf{3}$ & Silvicultura & 0,03 \\
\hline $\mathbf{4}$ & Floresta Secundária Média/Avançada & 0,01 \\
\hline $\mathbf{5}$ & $\begin{array}{l}\text { Sistema Viário / Estradas / Arruamento / Ferrovias / } \\
\text { Rodovias }\end{array}$ & 0,00005 \\
\hline $\mathbf{6}$ & Área Urbana & 0,00001 \\
\hline $\mathbf{7}$ & Solo Exposto / Pastagem & 0,404 \\
\hline $\mathbf{8}$ & Hidrografia / água & 0,00 \\
\hline
\end{tabular}

Para obtenção do Fator P - Práticas Conservacionistas, também foi utilizada a carta

de uso do solo da BHRC. O quadro 7 mostra a classificação utilizada:

Quadro 7 - Classificação adotada para o Fator P - Práticas Conservacionistas na BHRC

\begin{tabular}{|c|l|c|}
\hline CLASSE & \multicolumn{1}{|c|}{ USO DO SOLO } & PESO \\
\hline $\mathbf{1}$ & Mineração & 1,0 \\
\hline $\mathbf{2}$ & Afloramento Rochoso & 0,2 \\
\hline $\mathbf{3}$ & Silvicultura & 0,5 \\
\hline $\mathbf{4}$ & Floresta Secundária Média/Avançada & 0,2 \\
\hline $\mathbf{5}$ & $\begin{array}{l}\text { Sistema Viário / Estradas / Arruamento / Ferrovias / } \\
\text { Rodovias }\end{array}$ & 1,0 \\
\hline $\mathbf{6}$ & Área Urbana & 1,0 \\
\hline $\mathbf{7}$ & Solo Exposto / Pastagem & 0,5 \\
\hline $\mathbf{8}$ & Hidrografia / água & 1,0 \\
\hline
\end{tabular}

Definidos todos os parâmetros, a expressão da álgebra de mapas usada para a EUPS equação universal de perda do solo - na área da Bacia Hidrográfica do Ribeirão do Carmo foi a seguinte:

$$
\mathrm{EUPS}=[\mathrm{PNE}] *[\mathrm{C}] *[\mathrm{P}]
$$

Onde: $\mathrm{PNE}=$ Potencial Natural de Erosão = R.K.L.S ( $\mathrm{R}$ - erosividade da chuva, K erodibilidade do solo e LS - fator topográfico), 
$\mathrm{C}=$ fator uso e manejo (adimensional); e $\mathrm{P}=$ fator práticas conservacionistas (adimensional).

Os resultados foram classificados de acordo com a proposta de classes de perda de solo de FAO (1967), citado por Oka-Fiori (2004). Assim, a seguinte classificação dos graus de erosão foi empregada para a análise da Bacia do Ribeirão do Carmo (Quadro 8).

O resultado cartográfico final da elaboração e execução do modelo de cálculo de perda de solo a partir da Equação Universal de Perda de Solo pode ser observado na Figura 4.

Quadro 8 - Classificação adotada para a Perda de Solo na BHRC

\begin{tabular}{|c|c|}
\hline PERDA DE SOLO (ton/ha/ano) & GRAU DE EROSÃO \\
\hline$<10$ & Baixa \\
\hline $10-50$ & Média \\
\hline $50-200$ & Alta \\
\hline$>200$ & Muito Alta \\
\hline
\end{tabular}

Fonte: FAO (1967 segundo Oka-Fiori, 2004).

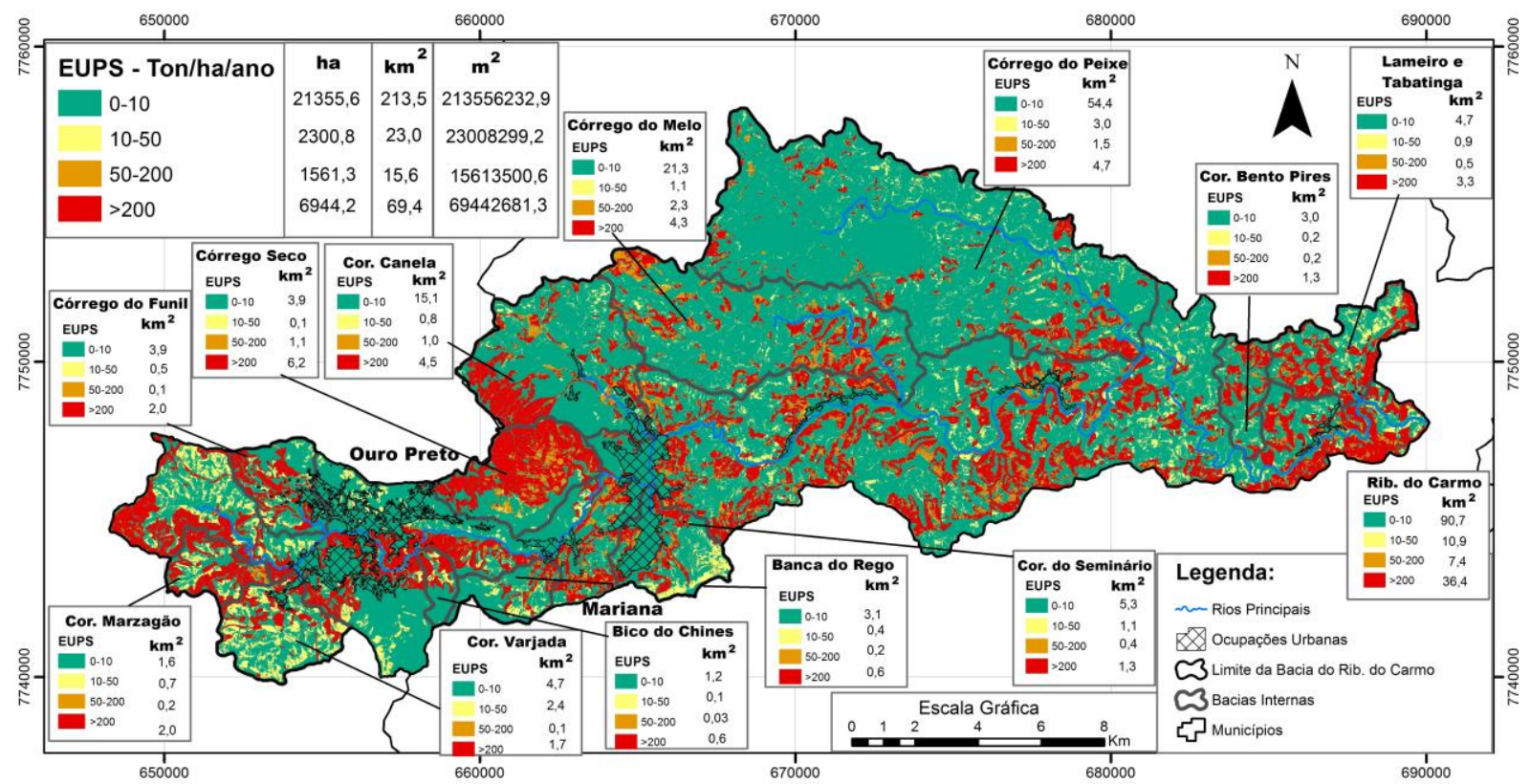

Figura 4 - Carta de Perda de Solo da Bacia do Ribeirão do Carmo.

O mesmo procedimento adotado para o cálculo do PNE foi reproduzido e para uma melhor visualização dos resultados obtidos após o processamento dos dados, estes foram apresentados para a área total da BHRC e para as bacias interiores mais importantes (Quadro 9).

Quadro 9 - Classes de Perda de Solo ao longo da Bacia do Ribeirão do Carmo segundo a EUPS.

\begin{tabular}{|l|c|c|c|c|}
\hline & \multicolumn{4}{|c|}{ ÁREA DAS CLASSES DE EROSÃO $\left(\mathbf{k m}^{2}\right)$} \\
\hline BACIA HIDROGRÁFICA & BAIXA & MÉDIA & ALTA & MUITO ALTA \\
\hline Ribeirão do Carmo & 213,55 & 23,00 & 15,61 & 69,44 \\
\hline Córrego Marzagão & 1,68 & 0,71 & 0,22 & 2,08 \\
\hline Córrego Varjada & 4,72 & 2,48 & 0,17 & 1,71 \\
\hline Ribeirão do Funil & 3,94 & 0,57 & 0,10 & 2,05 \\
\hline Córrego Bico do Chinês & 1,20 & 0,18 & 0,03 & 0,61 \\
\hline Córrego Banca do Rego & 3,13 & 0,49 & 0,20 & 0,65 \\
\hline Córrego Seco & 3,90 & 0,18 & 1,11 & 6,20 \\
\hline Córrego do Seminário & 5,36 & 1,13 & 0,43 & 1,39 \\
\hline Córrego Canela & 15,14 & 0,81 & 1,09 & 4,54 \\
\hline Córrego do Melo & 21,35 & 1,18 & $2.308,82$ & 4,33 \\
\hline Ribeirão do Peixe & 54,48 & 3,03 & 1,59 & 4,74 \\
\hline Córrego Bento Pires & 3,03 & 0,24 & 0,26 & 1,31 \\
\hline $\begin{array}{l}\text { Córregos Lameiro } \\
\text { Tabatinga }\end{array}$ & 4,78 & 0,98 & 0,55 & 3,31 \\
\hline \multicolumn{1}{|c|}{ Total: } & $\mathbf{2 9 4 , 0 2}$ & $\mathbf{1 0 0 , 1 1}$ & $\mathbf{6 5 , 8 6}$ & $\mathbf{2 7 , 6 5}$ \\
\hline
\end{tabular}




\section{INVENTÁRIO DE FEIÇÕES MORFOLÓGICAS E CICATRIZES DE MOVIMENTOS DE MASSA}

Segundo Fernandes \& Amaral (1996), a elaboração de um Inventário de Movimentos de Massa vem garantir o registro dos processos ocorridos no passado e no presente, gerando assim um banco de dados de análise que pode ser utilizado para a previsão de ocorrências no futuro, bem como para a análise dos fatores que influenciam na deflagração destes movimentos.

Bonuccelli (1999) ressalta que para a minimização dos problemas relacionados à ocorrência dos movimentos gravitacionais de massa, é necessário executar o levantamento dos processos e dos atributos que os influenciam, analisar a relação entre processos e atributos, elaborar um zoneamento ou uma hierarquização das áreas sujeitas a ocorrência desses fenômenos, realizar o levantamento e hierarquização dos danos que eventualmente possam ser produzidos pela deflagração de novos processos ou reativação de antigos e, finalmente, planejar ações e intervenções que permitam gerenciar e minimizar os possíveis danos.

Para a abordagem em questão, menos aprofundada do que as propostas por Fernandes \& Amaral (1996) e Bonuccelli (1999), a análise dos processos geodinâmicos ao longo da bacia teve por objetivo apenas identificar as principais feições morfológicas indicativas de movimentos de massa pretéritos deflagrados ao longo da BHRC espacializando, assim, os trechos e bacias interiores que mais contribuíram para a geração de sedimentos ao longo do sistema. A associação entre os pontos de geração de sedimentos por processo erosivos lineares e movimentos de massa associado a cartografia do potencial natural de erosão contribui para um melhor entendimento do meio físico da bacia e suas limitações, possibilita melhor entender o nível de assoreamento atual da PCH Furquim, construída no exutório da bacia, bem como a proposição de medidas visando a preservação e reabilitação dos trechos mais críticos.

Em um primeiro momento foi elaborado um mapa de ocorrências de movimentos de massa nas áreas urbanas de Mariana e Ouro Preto, a partir da sistematização dos registros e/ou cadastros de ocorrências da Defesa Civil e

Corpo de Bombeiros. Para este trabalho foram utilizados os dados gerados por Bonuccelli (1999), Gomes (2005) e Castro (2006), complementados com a coleta e georreferenciamento dos boletins de Defesa Civil obtidos nos municípios de Mariana e Ouro Preto entre os anos de 2007 e 2013 (Figura 5). Não foi o objeto deste estudo a realização de correlações entre os movimentos de massa e índices de chuva, mas apenas visualizar a distribuição espacial das ocorrências visto que tais registros retratam a ação antrópica sobre os diferentes substratos das áreas ocupadas e/ou com alteração de uso. As figuras 6 e 7 exemplificam algumas das ocorrências ao longo da bacia cadastradas.

Em um segundo momento, executou-se o reconhecimento de feições morfológicas e cicatrizes de movimentos de massa indicativas de processos pretéritos deflagrados em eventos de chuva ao longo da BHRC, cuja análise foi realizada em três etapas: a primeira identificou as cicatrizes a partir das fotos aéreas e ortofotos do ano de 1986; a segunda seguiu o mesmo procedimento, mas utilizando-se da imagem ASTER (2006) e de imagens do Google Earth (2014) que recobrem a bacia. As figuras 8 e 9 exemplificam parte dos dados obtidos com os procedimentos executados nas etapas 1 e 2 .

A terceira e última etapa referiu-se à avaliação e identificação em campo dos dados gerados nas etapas $1 \mathrm{e} 2$, considerando às suas características gerais, dimensões, estado de atividades e localização. Os principais problemas observados foram os processos erosivos lineares e deslizamentos generalizados de solo e rocha, principalmente os deslizamentos translacionais rasos em solos de xistos e filitos nas cabeceiras da BHRC. A integração de todas as informações e sua inserção no banco de dados com delimitação em mapa (Figura 10) permitiu, além de uma análise espacial dos processos, a relação destes com as unidades geológicas, com o uso e ocupação do solo urbano e rural, bem como permitirá a validação de análises de suscetibilidade geradas, e consequentemente, a proposição de diretrizes para o uso adequado do território. 


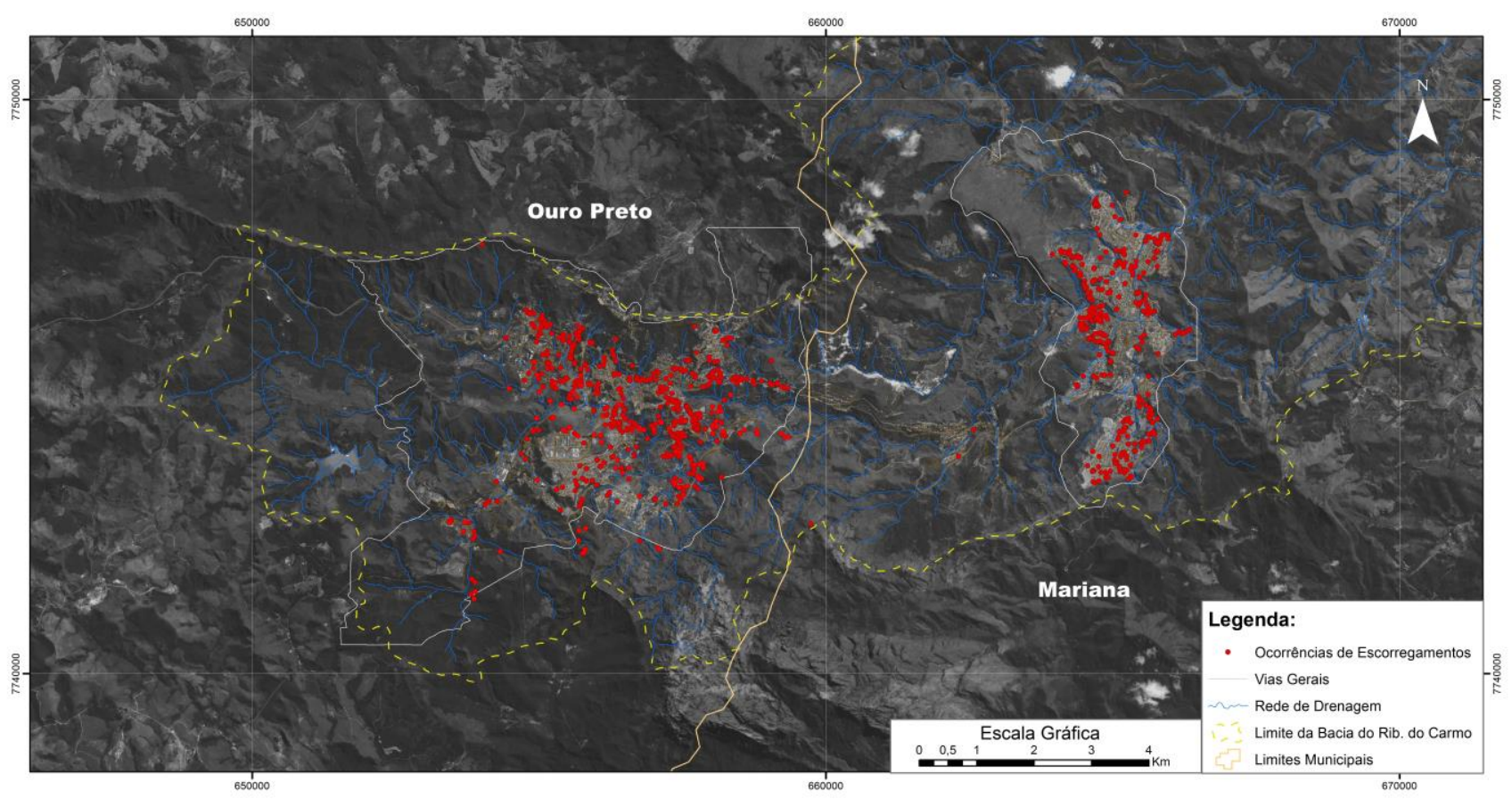

Figura 5 - Distribuição das ocorrências de movimentos de massa para as áreas urbanas de Mariana e Ouro Preto com registro nas Defesas Civis e Corpo de Bombeiros, entre os anos de 1994 e 2013.
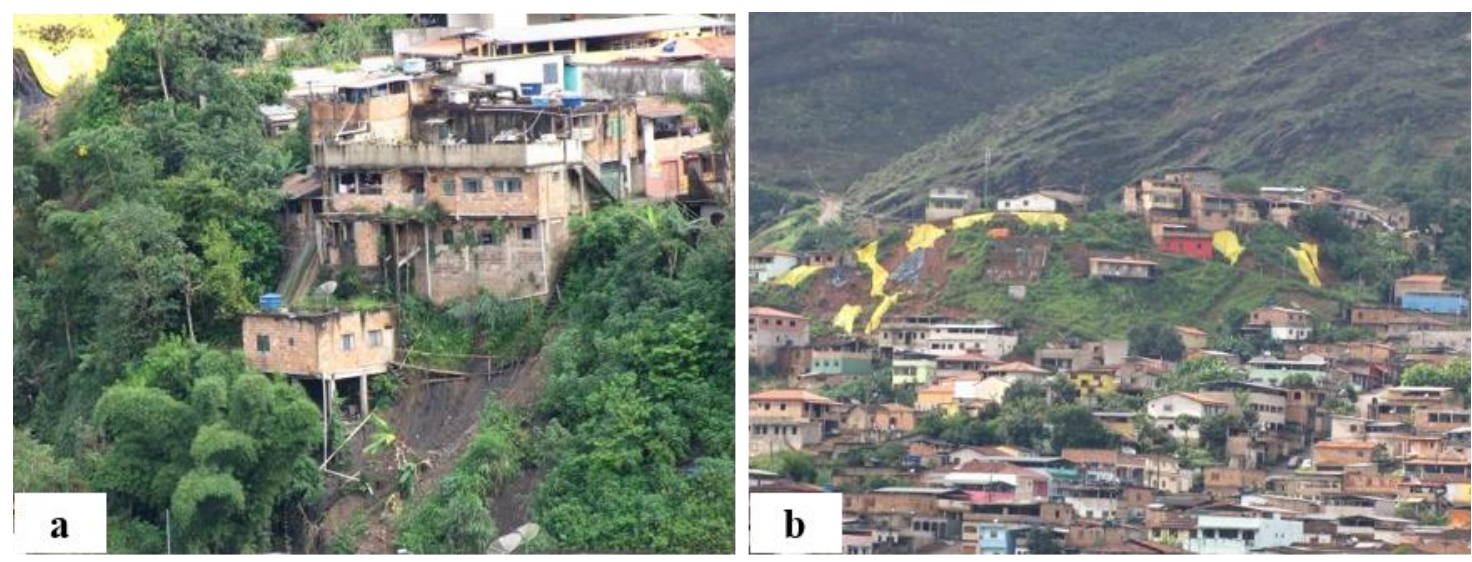

Figura 6 - a. Deslizamento Bairro São Gonçalo, Mariana, 2012; b. Deslizamento Bairro Cabanas, Mariana, 2012.
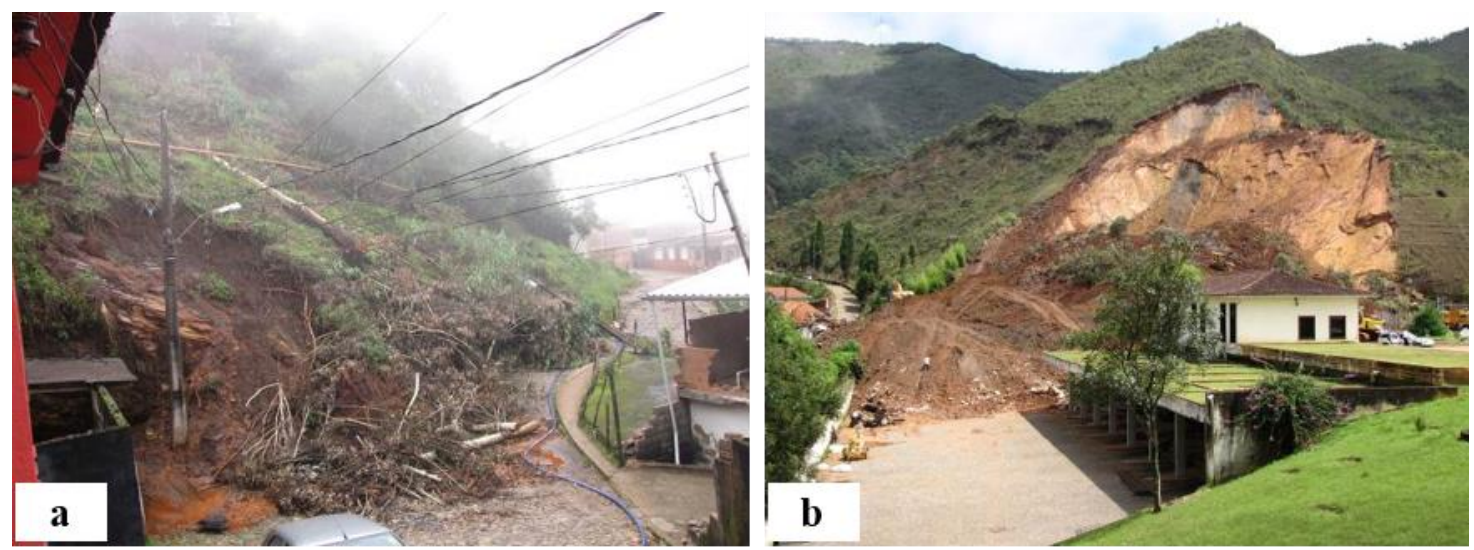

Figura 7 - a. Deslizamento Rua Treze de Maio, Ouro Preto, 2012; b. Rua Padre Rolim, em frente à Rodoviária de Ouro Preto, 2012 

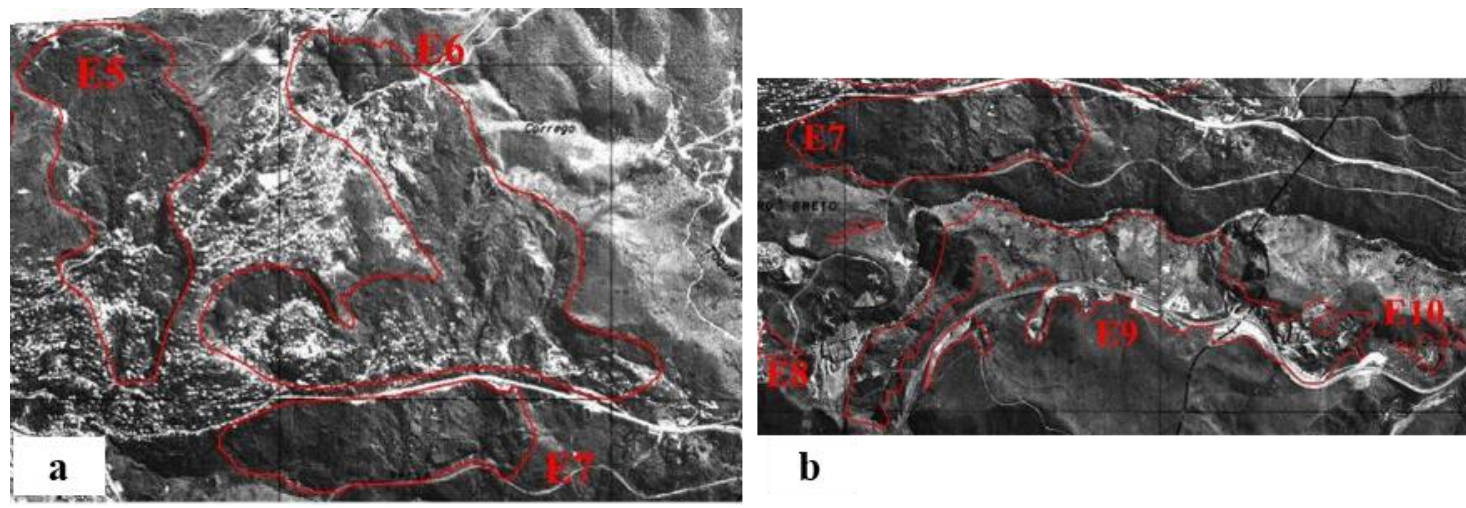

b

Figura 8 - a. Serra de Ouro Preto. Área intensamente minerada no século XVII com posterior ocupação desordenada;

b. Feições erosivas e deslizamentos translacionais rasos de solo e rocha. MG 262, saída para Mariana.
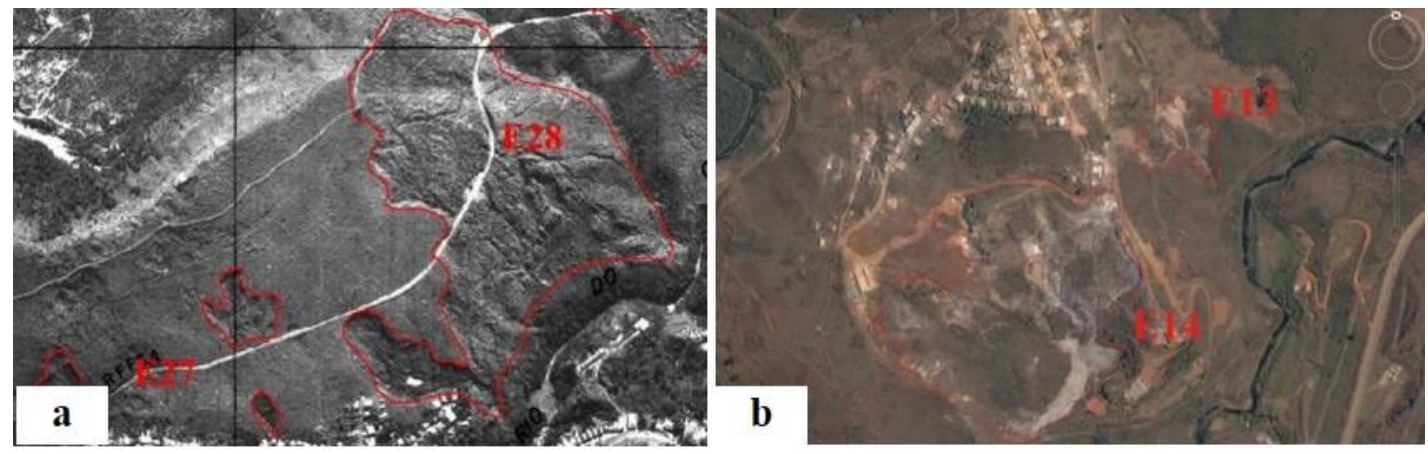

Figura 9 - a. Charneira do Anticlinal de Mariana. Contato entre os itabiritos resistentes da formação ferrífera com os xistos alterados do Grupo Nova Lima; Processos erosivos lineares associados a deslizamentos translacionais rasos de solo. Antiga Mina de Pirita não reabilitada.

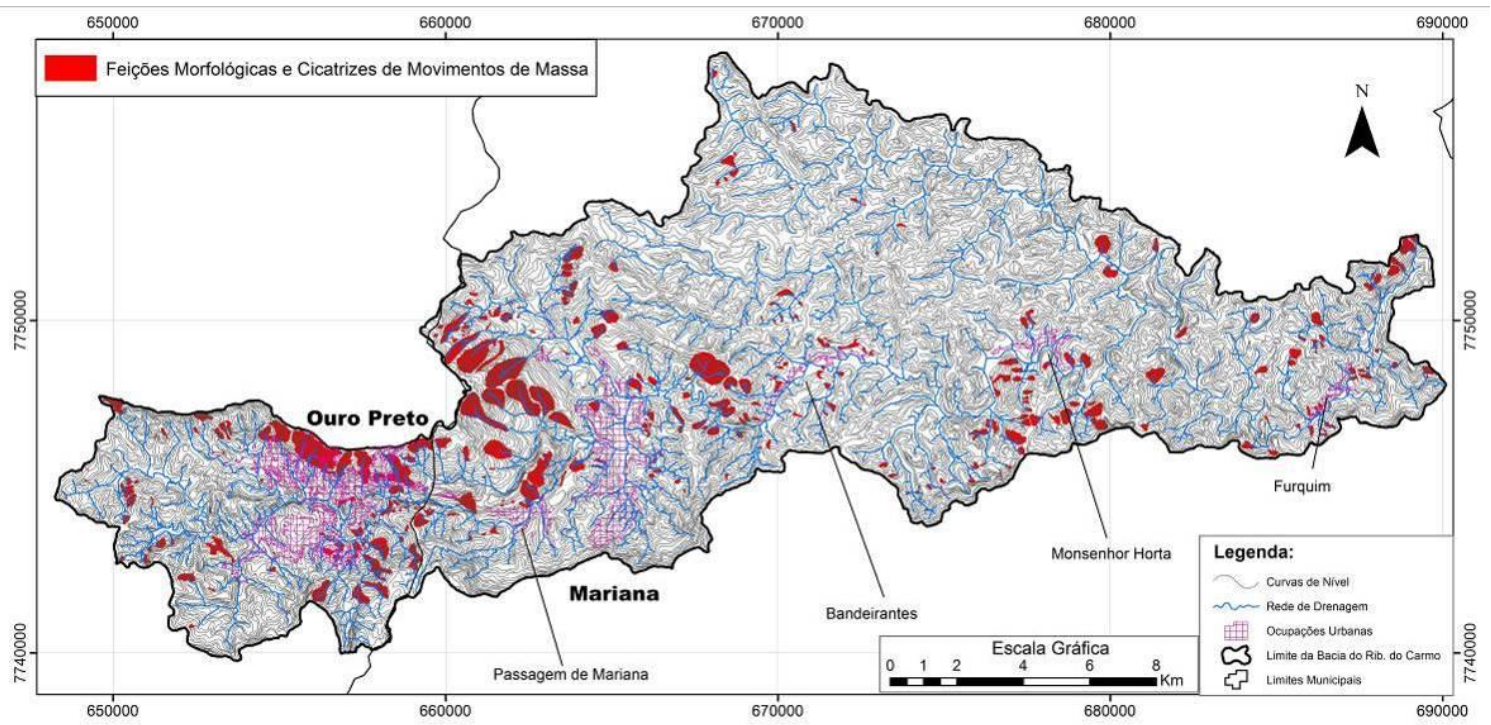

Figura 10 - Processos geodinâmicos, cicatrizes e feições morfológicas identificadas ao longo da bacia do Ribeirão do Carmo.

\section{CONCLUSÃO}

$\mathrm{O}$ estudo dos processos erosivos dos solos na BHRC implicou, necessariamente, no conhecimento das características geológicas, geomorfológicas, pedológicas, dos aspectos da vegetação e das condições climáticas da área de estudo, que condicionam o desenvolvimento de processos geodinâmicos, como movimentos de massa, erosão e transporte e deposição de sedimentos. Estes processos, quando ativos, podem causar inúmeros problemas no que tange ao uso e ocupação do solo urbano e rural. Por outro lado, as intervenções antrópicas inadequadas, como práticas de mineração e agrosilvipastoris, com a substituição da cobertura natural e alterações na rede de drenagem, geram condições facilitadoras para a deflagração e/ou ampliação de processos erosivos que originam ravinas e até mesmo voçorocas aumentando, 
significativamente, o volume de sedimentos transportados para os canais fluviais.

A bacia do Ribeirão do Carmo possui declive acentuado na cabeceira, englobando a área urbana do município de Ouro preto, até o Distrito de Passagem de Mariana, sendo os terrenos neste trecho mais susceptíveis ao desenvolvimento de processos erosivos e escorregamentos translacionais rasos. Entretanto, embora a porção oeste possua maior propensão para a geração de sedimentos, a declividade mais acentuada faz com que estes ao chegarem no Ribeirão do Carmo sejam transportados e depositados na porção central da bacia, principalmente ao longo do trecho ocupado pela sede do município de Mariana, bem como ao longo dos distritos de Bandeirantes e Monsenhor Horta.

Soma-se ao impacto oriundo pela geração e transporte de sedimentos ao longo da bacia, o retrabalhamento contínuo deste material pela erosão das margens dos canais, gerando um volume significativo de sedimentos recolocados diretamente nos cursos principais e, consequentemente, para o Ribeirão do Carmo. Estudos voltados para um melhor controle e mitigação desses processos devem ser desenvolvidos, sendo entre outras ações importantes, além do controle das fontes geradoras de sedimentos, à fiscalização para impedir atividades de garimpo, cada vez mais comuns, e à manutenção da mata ciliar, principalmente em bacias de médio porte como esta.

Outra causa importante na geração de sedimentos ao longo da BHRC refere-se às vias veiculares (rodovias, estradas vicinais e vias urbanas), pelo fato do sistema de drenagem pluvial conduzir um volume significativo de sedimentos gerados nos taludes de corte e aterro que não foram devidamente protegidos, além da ausência e/ou ineficiência do sistema de drenagem existente (canaletas de crista, berma, pé, caixas coletoras e dissipadoras e escadas hidráulicas), acarretando no lançamento indiscriminado das águas superficiais ao longo das encostas ás margens das rodovias e vias o que, consequentemente contribui para a deflagração e evolução de inúmeros processos geodinâmicos superficiais, como observado ao longo da Rodovia dos Inconfidentes e MG 262.
Em bacias hidrográficas medianas e pequenas como a BHRC, o diagnóstico adequado do meio físico e, no caso, a identificação dos processos geodinâmicos em atividade ao longo da bacia, possibilita através da integração das informações obtidas, a proposição de ações a curto e médio prazo para o controle do uso do solo. Entre as diversas ações que podem ser iniciadas destacam-se o reflorestamento das áreas identificadas como de elevado potencial natural a erosão, não agrícolas ou de baixa produtividade; a pre-servação/reabilitação das matas ciliares; o contro-le de focos erosivos identificados; a informação pública visando a adoção de práticas agrícolas utilizadas na conservação do solo, mesmo que para produções pequenas; entre outras. No caso da bacia do Ribeirão do Carmo, estas ações teriam grande importância em decorrência dos efeitos positivos que podem ser produzidos, principalmente ao longo das bacias interiores dos Córregos do Marzagão, Funil, Seco e Canelas.

Entretanto, deve-se atentar para o fato de que uma parcela importante na geração de sedimentos na BHRC, atualmente, está relacionada às zonas urbanas de Ouro Preto e Mariana, que apresentam um alto grau de interferência no meio físico (retaludamentos, desmontes, cortes e disposição de material sólido etc.), muitas vezes executada sem quaisquer controles técnicos adequados, culminando no incremento do carreamento de partículas para os cursos d'água em épocas chuvosas. Tal fato corrobora para a necessidade de se buscar a regulamentação dentro do código de obras dos municípios de diretrizes para a minimização e controle da geração de sedimentos nestas e em outras intervenções pontuais. Somam-se a estes problemas a necessidade de controle efetivo das atividades ilegais de garimpo, sejam elas fontes geradoras de sedimentos ao longo das encostas, sejam elas ocorrentes ao longo do leito do Ribeirão do Carmo, como constatado em diversos pontos de sua trajetória.

Assim, medidas mitigadoras para o problema da geração de sedimentos na bacia do Ribeirão do Carmo devem focar principalmente o ordenamento do uso do solo nas áreas urbanas de Ouro Preto e Mariana, em conjunto com uma série de ações de melhoria ambiental em toda bacia.

\section{REFERÊNCIAS}

BALTAZAR, O.F.; BAARS F.J.; LOBATO, L.M.; REIS, L.B.; ACHTSCHIN, A.B.; BERNI, G.V.; SILVEIRA, V.D.. Mapa
Geológico de Mariana na Escala 1:50.000 com Nota Explicativa. In: Projeto Geologia do Quadrilátero 
Ferrífero - Integração e Correção Cartográfica em SIG com nota explicativa. CODEMIG. Belo Horizonte, 2005.

BELLINAZI JUNIOR, R.; BERTOLINI, D.; LOMBARDI NETO, F. Ocorrência de erosão rural no Estado de São Paulo. In: SIMPÓSIO SOBRE CONTROLE DE EROSÃO RURAL NO ESTADO DE SÃO PAULO, 1981, São Paulo. Anais... São Paulo: IBGE, p. 117-137, 1981.

BERTONI, J. \& LOMBARDI NETO, F. Conservação do Solo. Livroceres. 392 p. 1985.

BERTONI, J. O espaçamento de terraços em culturas anuais, determinado em função das perdas por erosão. Bragantia, v. 18, p. 113-140, 1959

BERTONI, J. \& LOMBARDI NETO, F. Conservação do Solo. $3^{\text {a }}$ ed., Ícone Editora, São Paulo. 1993.

BONUCCELLI, T. J. Estudo dos movimentos gravitacionais de massa e processos erosivos na área urbana de Ouro Preto MG. São Carlos, 1999. 191p. Tese (Doutorado) - Escola de Engenharia de São Carlos, Universidade de São Paulo.

CASTRO, J. M. G. Pluviosidade e Movimentos de Massa nas encostas de Ouro Preto. Ouro Preto, 2006. 138 p. Dissertação (Mestrado em Engenharia Civil) - Departamento de Engenharia Civil, Universidade Federal de Ouro Preto.

CASTRO JUNIOR, R.M. DE. Zoneamento e Diagnóstico Geoambiental da Bacia do Rio Castelo usando Geoprocessamento. Ouro Preto, 2008. 264p. Tese (Doutorado) - Universidade Federal de Ouro Preto. Escola de Minas. Departamento de Geologia.

COOKE, R.U. \& DOORNKAMP, J.C. Geomorphology in Environmental Management. 2nd Edition, Oxford University, Clarendon Press, Oxford. 410 p. 1990.

CPRM, Levantamentos Geológicos Básicos do Brasil, Mariana - Folha SF.23-XB-1. Estado de Minas Gerais. Escala 1:100.000. In: BALTAZAR, O.F \& RAPOSO, F.O. (Coordenadores). Brasília, DNPM/CPRM. 196 p. 1993.

DENARDIN, J.E. Erodibilidade de solo estimada por meio de parâmetros físicos e químicos. Piracicaba, 1990. 81 p. Tese (Doutorado em Agronomia - Solos e Nutrição de Plantas) - Escola Superior de Agricultura Luiz de Queiroz, Universidade de São Paulo.

EMBRAPA - Empresa Brasileira de Pesquisa Agropecuária. 2006. Embrapa Solos. Disponível em: http://www.agrolink.com.br/ downloads/sistema-brasileiro-de-classificacao-dos-solos2006. Acessado em: 10/01/2015.

FAO - Organização das Nações Unidas para a Agricultura e a Alimentação. La erosión del suelo por el água. Algunas medidas para combatirla en las tierras de cultivo. Cuadernos de fomento agropecuário da Org. de Las Naciones Unidas, Roma, n. 81, $207 \mathrm{p}$.

FERNANDES \& AMARAL. Movimentos de massa: uma abordagem geológico-geomorfológica. In: GUERRA, A.J.T. e CUNHA, S.B. (Coordenadores). Geomorfologia e Meio Ambiente. Rio de Janeiro: Bertrand Brasil, p. 123-194, 1996.

GOMES, G. J. C. Análise temporal e espacial do risco de escorregamento em Ouro Preto-MG utilizando um Sistema de Informação Geográfica. Ouro Preto, 2005. 45 p Trabalho de Graduação, Engenharia Ambiental, Universidade Federal de Ouro Preto.

HERNANI, I. C.; SALTON, J. C.; FABRÍCIO, A. C.; DEDECEK, R.; ALVES JÚNIOR, M. Perdas por erosão e rendimentos de soja e de trigo em diferentes sistemas de preparo de um Latossolo Roxo de Dourados (MS). Revista Brasileira de Ciência do Solo, v. 21, n. 4, p. 667-676, 1997.

LOBATO, L.M.; BALTAZAR, O.F.; REIS, L.B.; ACHTSCHIN, A.B.; BAARS, F.J.; TIMBÓ, M.A.; BERNI, G.V; MENDONÇA, B.R.V. DE; FERREIRA, D.V. Projeto Geologia do Quadrilátero Ferrífero - Integração e Correção Cartográfica em SIG com nota explicativa. Belo Horizonte: CODEMIG. 1 CD-ROM, 2005.

LOMBARDI NETO, F. \& BERTONI, J. Erodibilidade de solos paulistas. Campinas, Instituto Agronômico. (Boletim Técnico 27), 12 p. 1975

LOMBARDI NETO, F. \& MOLDENHAUER, W.C. Erosividade da chuva: sua distribuição e relação com perdas de solo em Campinas, SP. Bragantia, v. 51, n. 2, p. 189-196, 1992.

MARQUES, J.J.G. DE S. e M. Estimativas e comparações dos fatores erosividade das chuvas e erodibilidade de solos com horizonte B textural no Brasil. Lavras, 1996. 119 p. Dissertação (Mestrado) - Universidade Federal de Lavras.

MOORE, I. \& G. BURCH.. Physical basis of the length-slope factor in the universal soil loss equation. Soil Science Society of America Journal, v. 50, p. 1294-1298, 1986a

MOORE, I. \& G. BURCH. Modeling erosion and deposition: topographic effects. Transactions of the ASAE, v. 29, n. 6, p. 1624-1640, 1986b.

MOPT. Guia para la elaboracion de estudios del medio fisico. Centro de Estudios de Ordenancia del Territorio y Medio Ambiente - Ministerio de Obras Publicas y Urbanismo, Madrid, 1992

OKA-FIORI, C.; FIORI, A.; HASUI, Y. Tolerância de perdas de solo na bacia do Rio Itiquira, Mato Grosso, Brasil. Boletim Paranaense de Geociências, n. 54, p. 83-99, 2004.

PINTO, S.A.F. Contribuição metodológica para análise de indicadores da erosão do solo utilizando técnicas de sensoriamento remoto, geoprocessamento e modelo predictivo. Rio Claro, 1995. Tese (Livre-Docência) Instituto de Geociências e Ciências Exatas, Universidade Estadual Paulista.

RADAMBRASIL. Levantamento de recursos naturais. Rio de Janeiro: Projeto RADAMBRASIL. v. 32.775 p., 1983.

RIBEIRO, L.S. \& ALVES, M.G. Quantificação de perda de solo por erosão no município de Campos dos Goytacazes/RJ através de técnicas de geoprocessamento. In: SIMPÓSIO BRASILEIRO DE SENSORIAMENTO REMOTO, 12. 2007, Florianópolis. Anais... Florianópolis: INPE, 2007, p. 3039-3046.

RIBEIRO, S.L. Aplicação do sistema de informação geográfica nacional ao estudo de erosão dos solos por meio do modelo EUPS na microbacia hidrográfica do Ribeirão Araquá-SP. Rio Claro, 2000. Dissertação (Mestrado em Geografia). Instituto de Geociências e Ciências Exatas, Universidade Estadual Paulista.

RIGHETTO, A.M. Hidrologia e Recursos Hídricos. São Carlos: EESC/USP, 840 p., 1998.

SILVA, M. L.N.; CURI, N.; LIMA, J.M. DE; FERREIRA, M.M. Avaliação de métodos indiretos de determinação da erodibilidade de Latossolos Brasileiros. Pesquisa Agropecuária Brasileira, v. 35, n. 6, p. 1207-1220, 2000.

SILVA, V.C. Estimativa da Erosão Atual da Bacia do rio Paracatu (MG/GO/DF). Pesquisa Agropecuária Tropical, v. 3, n. 34, 147-159, 2004.

STRAHLER, A.N. Quantitative analysis of watershed morphology. Transactions of the American Geophysical Union, v. 38, n. 913-920, 1957.

VALÉRIO FILHO, M. Técnicas de geoprocessamento e sensoriamento remoto aplicadas ao estudo integrado de bacias hidrográficas. In: PEREIRA, V.P.; FERREIRA, M.E. CRUZ, M.C.P. (Coord.). Solos altamente suscetíveis à erosão. Jaboticabal, FCAV/UNESP/SBCS. p. 223-242, 1994.

WISCHMEIER, W.H. \& SMITH, D.D. Predicting Rainfall Erosion Losses: A Guide to Conservation Planning. Washington: United States Department of Agriculture, 58 p. (Agriculture Handbook, 537), 1978.

Manuscrito recebido em 19 de julho de 2016 Revisado e aceito em 30 de novembro de 2016 